\title{
Aventuras de diagrama no país dos signos
}

Renira Rampazzo Gambarato

Pontifícia Universidade Católica/PUC-SP (doutoranda) 


\section{Resumo}

Este artigo aborda as variabilidades do conceito de diagrama pelo viés da Teoria Geral dos Signos ou Semiótica, de Charles Sandres Peirce (1839-1914), e da Teoria Geral dos Sistemas, de Mario Bunge (1919-...). Etimologicamente, diagrama significa através da linguagem: diágramma, do grego, nasce da junção de dia (através de) e gramma (medida de linguagem). No senso comum, seu significado se restringe a um gráfico; o que absolutamente não corresponde à complexidade do termo. Por se tratar de uma representação visual, os diagramas trazem aos nossos olhos a possibilidade de observar as relações neles contidas, relações estas que não necessariamente estavam visíveis antes da construção do diagrama.

\section{Palavras-chave}

diagrama, sistema, semiótica

\section{Abstract}

This article approaches the variabilities of the diagram concept for the inclination of the Signs' General Theory or Semiotics from Charles Sandres Peirce (1839-1914) and the Systems' General Theory from Mario Bunge (1919 -...). Etymologically, diagram means through the language: diágramma (Greek), comes from the junction of dia (through) and gramma (language measure). In the common sense, it means just a graph, what absolutely doesn't correspond to the complexity of the term. For treating of a visual representation the diagrams bring to our eyes the possibility to observe the relations in them contained, relations that were not necessarily visible before the construction of the diagram.

\section{Key words}

diagram, system, semiotics 


\section{A}

convivência com diagramas é cotidiana. No entanto, comumente não nos atentamos (nem mesmo os designèrs) à sua real significação e desdobramentos. Etimologicamente, diagrama signifíca através da linguagem: diágramma, do grego, nasce da junção de dia (através de) e gramma (medida de linguagem). No senso comum, seu significado se restringe a um gráfico, o que absolutamente não corresponde à complexidade do termo.

No intuito de investigar os meandros e variabilidades do conceito de diagrama, vamos nos valer, sóbremaneira, da abordagem semiótica e sistêmica. A ênfase na Teoria Geral dos Signos ou Semiótica, de Charles Sandérs Peirce (1839-1914), e na Teoria Geral de Sistemas, segundo Mario Bunge (1919-...), funda-se nas consonâncias que ambas compartilham:

Podemos defini-la [semiótica] como Ciência Geral dos Signos. Se é assim, cuidará também dos sistemas de signos, logo de todas as linguagens e, efetivadas as várias formas de semiose, tratará também de todos os sistemas de comunicação (Vieira, 2003, p.5).

Como vemos, semiótica, sistemas e linguagem se entrelaçam pelo fio condutor do signo, aquele que representa alguma coisa para uma mente, em uma certa medida. O signo é um primeiro que está em real relação de substituição com um segundo, seu objeto, por meio da geração de um terceiro, seu interpretante. Quando a mente opera essa substituiição, dá-se origem ao interpretante. A essa ação contínua do signo, gerando interpretantes ad infinitum, denominamos semiose.

Peirce enfatiza a

noção de signo ou linguagem como mediação entre mente e matéria. A polaridade entre o mundo da mente e o da 
matéria, o interior e o exterior, psíquico e fisico, só pode ser superada no momento em que se introduz o único elemento mediador, o signo, através do qual esses dois mundos se interseccionam. (Santaella, 1992, p.104)

É nesse pais dos signos que legitimamente encontramos os diagramas (através da linguagem).

\section{Aventuras de diagrama no país dos ícones}

A Semiótica peirceana, ou lógica das linguagens, nasce no interior da filosofia de Peirce, mais especificamente como uma das Ciências Normativas, na seqüência da Estética e Ética. Sua finalidade é a formação de pensamentos lógicos, signos em comunhão com a ética e a estética. Os signos se subdividem em tricotomias segundo suas características. Uma das mais importantes é aquela que classifica os signos conforme sua relação com seu objeto, podendo ser: ícone, índice, símbolo. O ícone é um signo de semelhança com o objeto, mas que não depende da sua existência para significar. Mantém uma analogia com o objeto por meio da apropriação de alguma qualidade essencial dele. Peirce, dando seqüência à sua estrutura triádica, subdividiu os ícones (ou_hipoícones) em três tipos: imagens, diagramas e metáforas.

Hipoícones podem ser, simplificadamente, divididos conforme o modo de Primeiridade do qual partilhem. Aqueles que partilham simples qualidades, ou Primeira Primeiridade, são imagens; aqueles que representam as relações (...) das partes de uma coisa por relações análogas às suas próprias partes, são diagramas; aqueles que representam o caráter representativo de um representamen pela representação de um paralelismo com alguma outras coisa, são metáforas (CP 2.277).

O ícone é o único caminho para a expressão de novas idéias. E o diagrama, enquanto um tipo específico de ícone dedicado a trazer à tona esse potencial criativo, explora o inesperado no interior do código: 
No País das Maravilhas, signos icônicos são, às vezes, auxiliares semióticos em meio à desorientação, mas outras vezes funcionam também como surpresa, revelando um potencial até então desconhecido de criatividade. Essa criatividade é explorada com ícones da categoria imagem e da categoria dos diagramas. (Nöth, 1995b, p.120)

Vejamos algumas definições de diagrama em Peirce:

Ícones são especialmente requisitados para o raciocinio. Um diagrama é, principalmente, um icone, e um icone de relações inteligiveis ( $\mathrm{CP} 4.531$ ).

Um diagrama deve ser tão icônico quanto possivel; isto é, deve representar relações por meio de relações visiveis análogas a elas (CP 4.433).

Um diagrama geométrico ou arranjo de simbolos algébricos é construido de acordo com um preceito abstratamente dado, e entre as partes de cada diagrama ou arranjo certas relações são observadas para obter outras além daquelas que foram expressadas no preceito (CP 2.216).

Eu chamo o signo que representa alguma coisa meramente porque se assemelha a ela, um icone. Icones são completamente substituidos por seus objetos tão dificilmente quanto são distinguidos deles. Assim são os diagramas da geometria. Um diagrama, certamente, não obstante tenha uma significação geral, não é um icone puro; mas no meio do nosso raciocínio nós esquecemos essa abstração em grande parte, e o diagrama é para nós a coisa. Contemplando uma pintura, existe um momento quando nós perdemos a consciência de que a pintura não é a coisa, a distinção do real e da cópia desaparece, e isso é para o momento um puro sonho - nenhuma existência particular, e ainda nenhuma geral. Nesse momento nós estamos contemplando um icone (CP 3.362). 
Assim, o diagrama é um ícone de relações entre suas partes constituintes, relações estas que não necessariamente estavam visíveis antes da construção do diagrama. Esta característica encerra o potencial abdutivo desse tipo particular de signo.

O geômetra desenha um diagrama que, se não é exatamente uma ficção é, no mínimo, uma criação e, pela observação desse diagrama, ele está apto a sintetizar e mostrar relações entre elementos que antes pareciam não ter relação necessária. A realidade nos compele a colocar algumas coisas numa relação muito próxima e outras menos, num sentido altamente complexo e de uma maneira ininteligivel; mas isso é a genialidade da mente, que pega todos esses sinais de sentido, acrescenta imensamente a eles, os torna precisos e os mostra de uma forma inteligivel nas intuições de espaço e tempo (CP 1.383).

O caráter icônico dos diagramas tem, justamente, a função de permitir a revelação de verdades inesperadas, mesmo que não sejam observadas semelhanças explícitas entre o diagrama e seu objeto.

Um diagrama nasce de associações, relaciona e integra idéias que já existiam previamente, mas que não eram percebidas, não estavam conectadas, desveladas. Permite visualizar as relações entre as idéias, representando-as em integração, de modo que explicite o que anteriormente não era percebido. Peirce resgata Kant para esclarecer que novas descobertas decorrem de um diagrama, ainda que não tenham sido previstas:

Kant está inteiramente correto ao dizer que (...) o matemático utiliza o que, em geometria, é chamada uma construção, ou um diagrama geral, ou um arranjo visual de caracteres ou linhas. Tal construção é formada de acordo com um preceito fornecido pela hipótese. Uma vez formada, a construção é submetida ao escrutínio da observação, e novas relações são descobertas entre as partes não apresentadas no preceito pelo qual ela foi formada (CP 3.560). 
A partir daqui fica evidente:

$1^{\circ}$.) o caráter tácito de todo diagrama;

$2^{\circ}$.) o caráter abdutivo de todo diagrama;

$3^{\circ}$.) o caráter dedutivo de todo diagrama.

Parte do nosso conhecimento não pode ser expresso por palavras. Conhecemos e reconhecemos signos muito além do que conseguimos verbalizar, afinal nós podemos saber mais do que nós podemos dizer (Polanyi, 1967, p.04). A estrutura básica do conhecimento tácito envolve sempre dois termos. Associamos um termo ao outro sem saber exatamente como, mas essa relação entre eles é lógica. Conhecemos o primeiro termo apenas pela correspondência ao segundo em função da nossa consciência.

Todo raciocínio necessário [dedução] é, sem exceção, diagramático. Isto é, nós construímos um icone a partir do nosso preceito hipotético [abdução] das coisas e prosseguimos observando-o. Essa observação nos permite suspeitar que alguma coisa é verdadeira, que nós estamos ou não aptos a formular com precisão [conhecimento tácito] e nós prosseguimos questionando se isso é verdadeiro ou não (CP 5.162).

Por se tratar de uma representação visual, os diagramas trazem aos nossos olhos a possibilidade de observar as relações neles contidas. Disto decorre que o diagrama comporta tanto a abdução quanto a dedução. A filosofia peirceana dedica uma porção específica da sua Lógica ou Semiótica para os estudos desses tipos de raciocínio. A Lógica Crítica se vale dos estudos fornecidos pela Gramática Especulativa de Peirce para investigar as condições pelas quais os signos são conformados, as relações entre os vários tipos de raciocínio. Ressaltamos que a abdução é uma possibilidade lógica que pode, ou não, ser verdadeira. É o processo de formulação de hipóteses, de novas teorias, sem a estrita preocupação de confirmálas. Esta confirmação somente será alcançada com a aplicação da etapa dedutiva do raciocínio científico. $O$ argumento dedutivo é aquele necessário. 
O caráter abdutivo concernente a esse tipo de representação diagramática é responsável pelo potencial de descoberta e de inovação disponíveis na criação de ícones de relações. No entanto, o potencial heurístico não é restrito apenas à abdução, na medida em que a dedução extrai conseqüências necessárias da hipótese (Ibri, 1994, p.130). A descoberta decifra, desvenda algo previamente: existente. Dedução (...) requer uma atuação criativa da mente sobre seus diagramas como modo de desvelamento do que de mundo já estava contido geneticamente na abdução (Ibri, 1994, p.130-31). A dedução é reveladora da abdução:

(...) Dedução consiste em construir um ícone ou diagrama de relações cujas partes apresentarão uma completa analogia com aquelas partes do objeto de raciocínio, experimentando sobre essa imagem na imaginação e observando o resultado para descobrir relações não notadas e escondidas entre as partes (CP 3.363).

Ainda em Peirce, temos que um diagrama pode constituir um sistema de representação perfeitamente consistente, fundado sobre uma simples e fácil idéia básica inteligível (CP 4.418). No intuito de entendermos como os diagramas podem ser considerados sistemas, introduziremos os conceitos provenientes da Teoria Geral dọ Sistemas, na seqüệncia.

\section{Através dos sistemas e o que o diagrama encontrou lá}

A Teoria Geral de Sistemas foi, inicialmente, desenvolvida por Ludwig von Bertalanffy (1901-1972), em 1950. No entanto, não abordaremos seu enfoque clássico de metodólogia científica, optaremos pela ontologia científica (ou ciência geral da realidade) de Mario Bunge, que tem como foco as características estruturais dos sistemas.

Segundo Bunge, um sistema é um objeto complexo, cujos componentes estão mais inter-relacionados do que soltos (1979). A 
realidade é sistêmica e o universo é o sistema gerador de todos os outros sistemas. A realidade não é composta por sistemas isolados, aqueles que não trocam energia nem matéria, mas por sistemas abertos em algum nível: trocam energia e matéria com o ambiente.

A definição formal de sistema desenvolvida por Bunge ressalta exatamente esse aspecto de relação com o ambiente, pois relaciona as coisas entre si e elas.com o seu ambiente. O sistema S é uma tripla:ordenada onde:

$$
\begin{aligned}
& \mathrm{S}=\langle\mathrm{C}, \mathrm{A}, \mathrm{R}> \\
& \mathrm{C}=\text { coisa } \\
& \mathrm{A}=\text { meio:ambiente de } \mathrm{C} \\
& \mathrm{R}=\text { conjunto de relações } \\
& \mathrm{C} \mathrm{C} \mathrm{A}=\mathrm{E} \text { (coisa e ambiente são diferentes) }
\end{aligned}
$$

Bunge ainda apresenta um esquema funcional para a representação de sistemas, qual seja:

$$
\begin{aligned}
& \mathrm{S}=<\mathrm{M}, \mathbb{P}> \\
& \mathrm{S}=\text { sistema } \\
& \mathrm{M}=\text { substratum do qual é composto o sistema } \\
& \mathrm{IP}=\text { lista de propriedades que caracterizam o sistema }
\end{aligned}
$$

Um sistema pode ser representado por um substratum que se remeta à sua composição e uma lista de propriedades desse sistema. Considerando os sistemas abertos, essas propriedades costumam. variar no tempo, ou melhor, essas propriedades possuem intensidades que variam no tempo ${ }^{1}$ :

$$
\begin{aligned}
& \mathrm{IP}=\left\{\mathrm{p}_{\mathrm{i}}\right\} \\
& \mathrm{IP}=\text { conjunto de propriedades }
\end{aligned}
$$

1 Notas de aula: Disciplina Ciênciàis: Cogninitivas e da Informação; Prof. Dr. Jorge de Albuquerque Vieira; 08/04/2003. 
$\operatorname{IP}(t)=\{p ;(t)\}$

IP $(t)=$ conjunto de propriedades em função do tempo

$\mathrm{p}=$ propriedades

$\mathrm{t}=$ tempo

Para melhor descrever e perceber os processos associados aos sistemas é preciso considerar os parâmetros sistêmicos. Tais parâmetros são características que ocorrem em todo sistema, independentemente de suas particularidades, e se subdividem em: básicos ou fundamentais (permanecem em qualquer tempo, independente dos processos evolutivos) e evolutivos (podem flutuar no tempo, ao longo da evolução). Os parâmetros básicos são: permanência (sobrevivência, tendência a permanecer), meio-ambiente (todos os sistemas são abertos para um ambiente) e autonomia (função memória, estocagem de informações). Os parâmetros evolutivos se organizam de acordo com a seguinte hierarquia: composição, conectividade, estrutura, integralidade, funcionalidade, organização e complexidade. Pela pertinência do momento vamos abordar os parâmetros conectividade, integralidade e complexidade, relacionando-os com o diagrama.

\section{Conectividade}

Parâmetro que exprime a capacidade que os elementos constitutivos do sistema possuem de desenvolver um conjunto de relações ou conexões. Conexão é uma relação intensa que afetará a história de, pelo menos, um dos seus elementos. Relação esta na qual existe ação entre os elementos envolvidos.

Dados os conjuntos $\mathrm{A}$ e $\mathrm{B}$, temos o produto cartesiano $\mathrm{P}=\mathrm{A}$ $\mathrm{x} B$ definido assim:

$$
P=\{<x, y>/ x \in A \& y \in B\}
$$

P é construído pelos arranjos entre elementos de $\mathrm{A}$ e $\mathrm{B}$, mas pode haver alguma regra, lei ou restrição que guie a seleção desses 
pares ordenados. Assim sendo, a regra irá selecionar um subconjunto $\mathrm{R}$ (relação) que se dará por:

$$
R=\{<x, y>\subset P\}
$$

Outro forte traço da conectividade é a variação de intensidade das conexões no tempo. As conexões mantëm o sistema no tempo.

Dessa forma temos um aspecto da conectividade que responde por uma forma de estabilidade e permanência sistêmicas, que será chama Coesão. A coesão está próxima, em semiótica, ao conceito de sintaxe, uma propriedade construida sobre o conjunto $R$ de relações. A sintaxe é o conjunto de regras que subjaz às relações (Vieira, 2003, p. 24).

Ao considerarmos diagramas enquanto sistemas, ou seja, enquanto objetos complexos cujos componentes ou subsistemas estão conectados entre si e com o ambiente, temos que a conectividade é parâmetro essencial pará a dèscrição dessas relações internalizadas nos diagramas. Afinal, se em Peirce diagramas são ícones de relações que deixam aparecer à nossa mente verdades não antes previstas, podemos considerar que diagramas são sistemas, que ao trocarem energia entre seus subsistemas (elementos visuais constituintes) e com o ambiente (mente interpretante), nesta interface, geram a descoberta e a inovação tão particular desse tipo de signo.

Admitamos assim que a realidade é formada por sistemas abertos, tal que a conectividade entre seus subsistemas, com o conseqüente transporte de informação, gera a condição em que cada subsistema é mediado ou vem a mediar outros, comportando-se como signo, de acordo com a proposta de Peirce. Dessa forma, temos a possibilidade de conciliar a visão sistêmica com a semiótica peirceana, o que nos parece uma dilatação ontológica fértil para o estudo da complexidade (Vieira, 2003, p.13). 


\section{Integralidade}

É a estratégia que um sistema usa de se subdividir em subsistemas pela emergência de novas propriedades partilhadas. $O$ grau de integração depende das conexões entre os componentes do sistema com relação às ações de desintegração do ambiente (Bunge, 1979).

A integralidade, por exprimir a configuração por meio de subsistemas, interessa-nos particularmente por estar ligada à questão da forma. A forma surge da coesão dos subsistemas. A heterogeneidade (diferença) dos subsistemas é que delimita a forma. A integralidade refere-se à maneira pela qual os subsistemas estão conectados. Diagramas têm na sua forma ou configuração seu principal atributo. A integralidade dos seus subsistemas, ou sua forma, comunica o conteúdo (informação) a ser interpretado.

\section{Complexidade}

A complexidade pode se manifestar de variadas maneiras em meio aos parâmetros sistêmicos. É, por vezes, considerada um parâmetro livre e dificil de ser definido, mas está sempre presente. A complexidade pode ser o entrópico, o caótico, mas também o organizado, o organizado com qualidade, o estético, o axiológico... (Vieira, 2003, p.26)

Vamos abordar a complexidade por meio dos outros parâmetros aqui estudados: conectividade e integralidade. A conectividade, enquanto fonte de relações, pode apresentar complexidade no número e na diversidade destas relações. A integralidade advém da emergência de subsistemas, denotando aumento da complexidade sistêmica, tanto no número de subsistemas quanto na emergência de propriedades partilhadas.

Pela conectividade e integralidade, temos que a complexidade de um sistema está calcada na diferença, na heterogeneidade de seus elementos constituintes entre si e na relação com o ambiente. Estas diferenças, informação, explicitadas nos diagramas agem 
sobre nós. É a mediação sígnica enriquecida pela diversidade, complexidade.

Vieira coloca-nos o problema das definições da complexidade existente realmente nas coisas e da complexidade semiótica, aquela das nossas representações das coisas. No entanto, lembra-nos que toda definição depende de uma elaboração lingüística e que é bastante possível que a complexidade dos sistemas seja melhor percebida fora de nossas elaborações verbais. Assim, considera o conhecimento tácito como forma legítima de percepção da complexidade, ou das complexidades.

A fonte do conhecimento tácito seria a estratégia, altamente sofisticada, de mapear diversidade em nossos cérebros e mentes; ou seja, o tácito seria um código notavelmente complexo que reflete niveis notavelmente complexos de uma realidade: Nesse sentido, se chegamos a construir planos mentàis complexos contendo dimensões axiológicas várias, além de sentimentos e emoções, é porque essas representações representam algo do mundo objetivo, o que é concordante com a semiótica de Peirce e também com suá metafisica ou ontologia (Vieira, 2003, p.28).

Neste momento, retomamos o início de nossa abordagem dos diagramas, que cónsiderava seu caráter tácito na medida em que as representações diagramáticas informam e nos deixam perceber muito mais do que poderíamos somente pela elaboração lingüística: O diagrama encontra, tanto na Sẻmiótica quantó na Teoria Geral dos Sistemas, o país adequado para se estabelecer, pois, afinal, tudo não passa de signos. 


\section{Bibliografia}

BUNGE, M. 1979. Treatise on basic philosophy. v. IV: Ontology a world of systems. Amsterdam: Reidel.

BÜRDEK, B. E. 1999. Diseño - historia, teoría y práctica del diseño industrial. Tradução F. V. López-Manzanares. Barcelona: Gustavo Gili.

CARROLL, L. 1980. Aventuras de Alice no pais das maravilhas, através do espelho e o que Alice encontrou lá. Tradução Sebastião U. Leite. São Paulo: Summus.

EMMER, M. (org.) 1993. The visual mind: art and mathematics. Cambridge: MIT Press.

FERRARA; L. D. 1993a. Leitura sem palavras. São Paulo: Ática. 1993b. Olhar periférico. São Paulo: Edusp.

HARTSHORNE, C.; WEISS, P. E BURKS, A. (eds.) 1931-35 e 1958. Collected papers of Charles Sanders Peirce - 8 vols. Cambridge: Harvard University Press. (Forma usual de referência: $\mathrm{CP}+\mathrm{n}^{\circ}$. do volume $+\mathbf{n}^{\circ}$. do parágrafo).

IBRI, I. A. 1992. Kósmos noetós. São Paulo: Perspectiva e Holón.

1994. Kósmos poietikós - criação e descoberta na filosofia de Charles S. Peirce. Tese de doutorado. São Paulo: USP.

NÖTH, W. 1995a. Handbook of semiotics. Bloomington: Indiana University Press.

1995b. Panorama da semiótica - de Platão a Peirce. São Paulo: Annablume.

PEIRCE, C. S. 1974. Os pensadores. Tradução A. M. D’Oliveira e S. Pomerangblum. São Paulo: Abril Cultural.

1999. Semiótica. Tradução J. Teixeira Coelho Neto. São Paulo: Perspectiva.

POLANYI, M. 1967. The tacit dimension. New York: Doubleday.

SANTAELLA, L. 1992. A assinatura das coisas. Rio de Janeiro: Imago.

VIEIRA, J. A. 2003. "Semiótica e complexidade". In: I Jornada de estudos em semiótica e complexidade: sistemas e cognição-PUC São Paulo. 